\title{
Consumer Perception Concerning Apple Fruit Quality, Depending on Cultivars and Hedonic Scale of Evaluation - a Case Study
}

\author{
Cătălina DAN ${ }^{1}$, Corina ȘERBAN ${ }^{1,2}$, Adriana F. SESTRAS ${ }^{1 *}$, Mădălina MILITARU ${ }^{3}$, \\ Paula MORARIU ${ }^{1}$, Radu E. SESTRAS ${ }^{1}$ \\ ${ }^{1}$ University of Agricultural Sciences and Veterinary Medicine Cluj-Napoca, Romania; catalina.dan@usamvcluj.ro; \\ adriana.sestras@usamvcluj.ro (*orrespondingauthor);rsestras@usamvcluj.ro \\ ${ }^{2}$ Washington Tree Fruit Research Commission,Wenatchee,USA; corinaserban07@gmail.com \\ ${ }^{3}$ Research Institute for Fruit Growing Piteşti, Romania; madamilitaru77@yahoo.com
}

\begin{abstract}
The objective of this study was to analyse fruit quality through consumers' perceptions and their preferences revealed by two panel questionnaires. Among the most common apple cultivars on the Romanian markets, were chosen the ones existing simultaneously and continuously (over two-years, during January-March): 'Golden Delicious', 'Braeburn', 'Granny Smith', 'Red Delicious', 'Jonagold', 'Jonathan', 'Florina', 'Idared'. The consumers' panel for sensory evaluation was represented by students, who completed two types of questionnaires. Both questionnaires refer to foremost traits for dessert apple, such as fruit appearance (size, shape, color) and intrinsic peculiarities (pulp consistency, juiciness, taste, flavor). First questionnaire comprised different scales for the traits (1-3, 1-5 or 1-15), while the second one consisted of the hedonic scale (1-9) for all traits. For commercial appearance of the fruits were highlighted 'Idared', 'Granny Smith', 'Braeburn' and especially 'Jonagold'. 'Braeburn' was distinct by the highest quality taste (average grade 13.9 on the scoring taste scale 1-15) and also for fruit flavor. 'Granny Smith', a commercially attractive-looking fruit, received only an average of 6.2 for taste and 2.6 for flavor. 'Granny Smith' presented the largest value for the coefficients of variation for taste, this variety being preferred less by female than male tasters. Inconsistency of the market, prices and foreign assortment on Romanian market was illustrated by the lack of statistical correlations between commercial aspect of fruit and price. The study could provide useful background information for apples breeders, farmers and marketing fruits strategy. The use of different scales for panel evaluation, dependent on the relevance of traits, might be a proper solution for reducing bias. In this case, the 1-15 large scale for apple taste compared with lower ones for other traits assured a more appropriate image of the tasters' preferences.
\end{abstract}

Keywords: organoleptic analysis, coefficient of variability, correlation, panel, sensory evaluation

\section{Introduction}

Even though there are many varieties of apple, relatively few are widespread and widely cultivated in the world (Sestras, 2004). Hecke et al. (2006) considered that the range of apple cultivars in the European market is significantly reduced to no more than twelve. Thus, on the Romanian markets are prevailing fruits belonging to well-known apple cultivars, but obtained by farmers in different countries. Nowadays, if the origin of fruit and the cultivars do not influence consumer's choice (Denver, 2014; Racskó et al., 2009), consumers are increasingly interested in fruit qualities in connexion with the price and their socio-economic situation, therefore consumers' acceptance involves both the intrinsic and extrinsic product factors as well as cognitive, demographic, social and attitude factors (Bignami, 2003; Seppä, 2014).

Fruit quality represents an essential breeding objective, as the consumers' expectations are constantly growing (Harker et al., 2008; Seppä et al., 2013). Quality is a complex trait, dependent on morphologic and organoleptic characteristics of fruit (size, shape, skin color, flavor, taste, juiciness, crispness, firmness etc.), but in the same time influenced by agrotechnical practice, biochemical processes and nutritional richness of fruits (Abbott, 1999; Bonany, 2014; Sestras, 2004).

The importance of apples' quality in consumer purchasing is very important (Miller et al., 2005) and the need for a detailed, systematic evaluation of new apple cultivars has been recognized (Langford, 2000), because a one percent increase in quality could improve the demand for apples by 12 to $59 \%$ (Harker, 2002).

An apple has to fulfil numerous expectations so that it can be named "qualitative" by different types of consumers. Thus, the fruits have to be large enough (but not too big), overall agreeable outside aspect, nicely and uniform colored, the pulp has to be flavored, juicy and crispy (Gatti et al., 2011; Jenks and Bebeli, 2011; Seppä, 2014; Yahia, 1994). But even so, the demands are changing over time and the preferences may vary 
according to different trends; therefore, breeders also need to be up to date with these expectations of the consumers that may change the markets. In this regard, breeding programs should create a vast enough variability within the species, among which one can chose suitable cultivars depending on particular demands at some moment in time, but with tested traits, that proved to be constant through next generations (Byrne, 2012).

Apples are largely consumed as fresh fruit, but they can also be processed under different products (juices, gems, cider, baby food etc.) and therefore constitute a main ingredient in the human diet and the grocery industry. This is why the quality of apple cultivars should take into consideration also the final destination of the fruits (Endrizzi et al., 2015; Sestras, 2004).

The peculiarities of dessert apple, by this understanding fruit that are consumed fresh, are the so called 'quality elements', analysed through a tasting panel, based on a specific questionnaire. It is recommended that the tasters are untrained consumers, so that the evaluation can be as accurate as possible; this why usually regular consumers (with no experience in sensory tasting), children or students are taking part to the sensory evaluation (Popper, 2015).

Apple fruit size is not only a quality trait, but also a productivity indicator; it is genetically inherited, but strongly influenced by agrotechnical strategy too. The size is usually given by weight or diameter, while the volume may be also used (height $(\mathrm{mm}) \times$ radius $\left.\left.\left(\mathrm{mm}^{2}\right)\right) / 1000\right] \times 2.7$ (Brown, 1960). Janick et al. (1996) stated that the minimum diameter for dessert apple cultivars is $65 \mathrm{~mm}$, whereas the general accepted size for fruits is $140-175 \mathrm{~g}$, or $75-85 \mathrm{~mm}$ in circumference (Cimpoies et al., 2001). The shape of the apples is very diverse, given by height and diameter. It is desirable that the shape is uniform (Ardelean, 1994); populations may also differ in preferences for visual attributes (Hampson and Quamme, 2000). The skin color contributes to the commercial aspect, along with size and shape being the ones that attract buyers (Sestras, 2004). Intense colors are preferred, with wax on the surface. The pulp's color may differ among cultivars, but the general acceptance is that it should be clear, without color infiltrations. Flesh firmness is also a characteristic used to indicate fruit quality (Harker $e t$ al., 1996). The cultivars vary from soft to hard apples, but the favoured texture is crispy. After assessing a wide range of texture attributes including crispness, crunchiness, hardness, ease of breakdown by sensory interpretation or instrumental measurements, it was concluded that some textural differences between apples were not always adequately predicted by instrumental tests (Harker et al., 2002). Selecting for crispness instrumentally in apple breeding programs is notoriously difficult (Evans et al., 2010). Also, no instrumental measurement was considered a satisfactory predictor of sensory acceptability scores (Abbott et al., 2004). Consequently, apple breeders rely on sensory assessment for this important characteristic (Evans et al., 2010; Harker et al., 2008). The taste is essential when considering apple quality, which is the factor that influences the popularity of a cultivar and its presence on the market (Hampson et al., 2000). It is a long debate about the taste, but the general idea is that the components (mainly sugars and acids) that form the final mouth feel should be balanced and typical for apple (Janick and Moore, 1996; Seppä, 2014; Sestras, 2004; Yahia, 1994).
In addition to taste and texture sensations, the trace amounts of volatile components responsible for odour (more than 350 volatiles) offers much of the fruits' character (Yahia, 1994). The flavor is, along with the taste, the one that influence the most consumers preferences, therefore it is important to be pleasant and balanced.

Knowing the consumers demands and the trends that influence their expectations over time is concerning breeders, farmers, final or intermediary producers and market representatives.

Breeders should be included at the beginning of this circuit, by predicting the changes on fruits markets and by anticipating the specific demands and consumers preferences (Byrne, 2012; Endrizzi et al., 2015). Trends affect the objectives that breeders emphasize in their programs as they strive to anticipate the future needs of the fruit industry so that new cultivars can be created in corresponding directions.

The objective of the study was to analyse fruit quality of the most common varieties on the market and to evaluate the preferences of the consumers. In addition, the study may provide useful background information for apples breeders, local farmers and fruit marketing in Romania.

\section{Materials and methods}

\section{Experiment ground, premises}

The survey was done among fruit markets, hypermarkets, wholesalers and retailer shops from Cluj-Napoca, Romania, by pursuing the apple supply during January-March interval, over two consecutive years. The investigations were accomplished with the participation of students from Faculty of Horticulture, University of Agricultural Sciences and Veterinary Medicine Cluj-Napoca. The methodology was established in order to reduce the discrepancies among different locations or periods, as well as the lack of secured information about the income or output on the market, or in some cases, regarding the origin and the identification of the cultivars.

Among the most common apple cultivars on the prospected locations, were chosen for fruit quality analysis only the cultivars existing simultaneously and continuously (during two years, between January-March) in at least three locations. On these bases, the final cultivars evaluated were: 'Golden Delicious', 'Braeburn' (from Italy), 'Granny Smith', 'Red Delicious' (Greece), 'Jonagold', 'Jonathan', 'Florina', 'Idared' (Poland). The samples were collected randomly and the price was noted (lei/kg) (lei - Romanian currency).

\section{Tasting procedure for sensory evaluation}

The quality of apples was evaluated through two types of 'Tasting panel evaluation form', respectively questionnaires (Figs. 1 and 2). Both of the forms refer to same traits followed for dessert apples regarding appearance, or commercial aspect (size, shape, color) and intrinsic peculiarities such as pulps' consistency, juiciness, taste, flavor.

The tasting took place at University of Agricultural Sciences and Veterinary Medicine Cluj-Napoca, Romania; prior, some specific determinations were established to determine biometric traits: height $(\mathrm{H})$ and diameter $(\mathrm{D})$ of fruit, shape index $(\mathrm{H} / \mathrm{D})$, volume $(\mathrm{ml})$, weight $(\mathrm{g})$, but also soluble solids content ( ${ }^{\circ}$ Brix) and firmness $\left(\mathrm{N} / \mathrm{cm}^{2}\right)$. These characteristics are to be correlated further with the data resulted from the panel questionnaires. 
142

Tasters were represented by 40 students $(50 \%$ female and $50 \%$ male), as potential consumers, and were asked to fill in the two questionnaires in two phases, at an interval of one week in between; the quality of samples was the same in both weeks. The students did not followed at the evaluation moment any fruit growing trees, neither pomiculture nor pomology specialised courses, therefore the ground was as for untrained consumers.

The two tasting panel evaluation forms refer to the same traits, but differ in scales, which are chosen to be dependent on the importance of the trait when considering fruit quality.

Questionnaire 1 (Q1) is adapted from the model used by Romanian pomologists and pome breeders in the past and consists the following scales: 1-3 for size, shape, pulp color, consistency of pulp; 1-5 for fruit color, skin color, juiciness, flavor; 1-15 for taste (Fig. 1).

Questionnaire $2(\mathrm{Q} 2)$ is the 9-point hedonic scale model, which is most commonly used nowadays, with the extension of Kroll (1990) as he showed that a non-formal scale with nine "child friendly" verbal anchors ranging from "super good" (9) to "super bad" (1) may perform better (Popper, 2005) (Fig. 2).

The principle is the same for both questionnaires, for all traits, small marks indicating a negative impact upon tasters and high marks, in the superior part of the scales, regardless of which, indicating that favourable impressions prevail (Jemrić et al., 2012a). Also, the order of citing the traits on the evaluation forms was maintained the same, not to influence the data.

\footnotetext{
1. Name...

2. Occupation

3. Tasting location

5. Species (eg apple, pear, quince) .....
}

6. Evaluation of the fruits' quality traits using specific scale for each peculiarity

\begin{tabular}{|l|c|c|c|c|c|c|c|c|c|}
\hline Analysed traits & Scale & \multicolumn{5}{|c|}{ Sample (Cultivar, hybrid, selection) } \\
\hline 7. Exterior (commercial) aspect of fruits & (marks) & 1 & 2 & 3 & 4 & 5 & 6 & 7 & 8 \\
\hline a. Fruit size & $(1-3)$ & & & & & & & & \\
\hline b. Fruit shape & $(1-3)$ & & & & & & & \\
\hline c. Skin color & $(1-5)$ & & & & & & & & \\
\hline Total- Exterior aspect & $(3-11)$ & & & & & & & & \\
\hline 8. Pulp traits & (marks) & & & & & & & & \\
\hline a. Color & $(1-3)$ & & & & & & & & \\
\hline b. Consistency & $(1-3)$ & & & & & & & & \\
\hline c. Juiciness & $(1-5)$ & & & & & & & & \\
\hline d. Taste & $(1-15)$ & & & & & & & & \\
\hline e. Flavor & $(1-5)$ & & & & & & & & \\
\hline Total-Pulp traits & $(5-31)$ & & & & & & & & \\
\hline 9. General mark (total 7+8) & $(8-42)$ & & & & & & & & \\
\hline
\end{tabular}

10. The quality of samples according to the marks scored .......

11. Overall comments regarding the samples ......

Signature

Fig 1. Questionnaire for assessing fruit quality (cultivars, selections, hybrids) of apple, pear, quince (Q1)

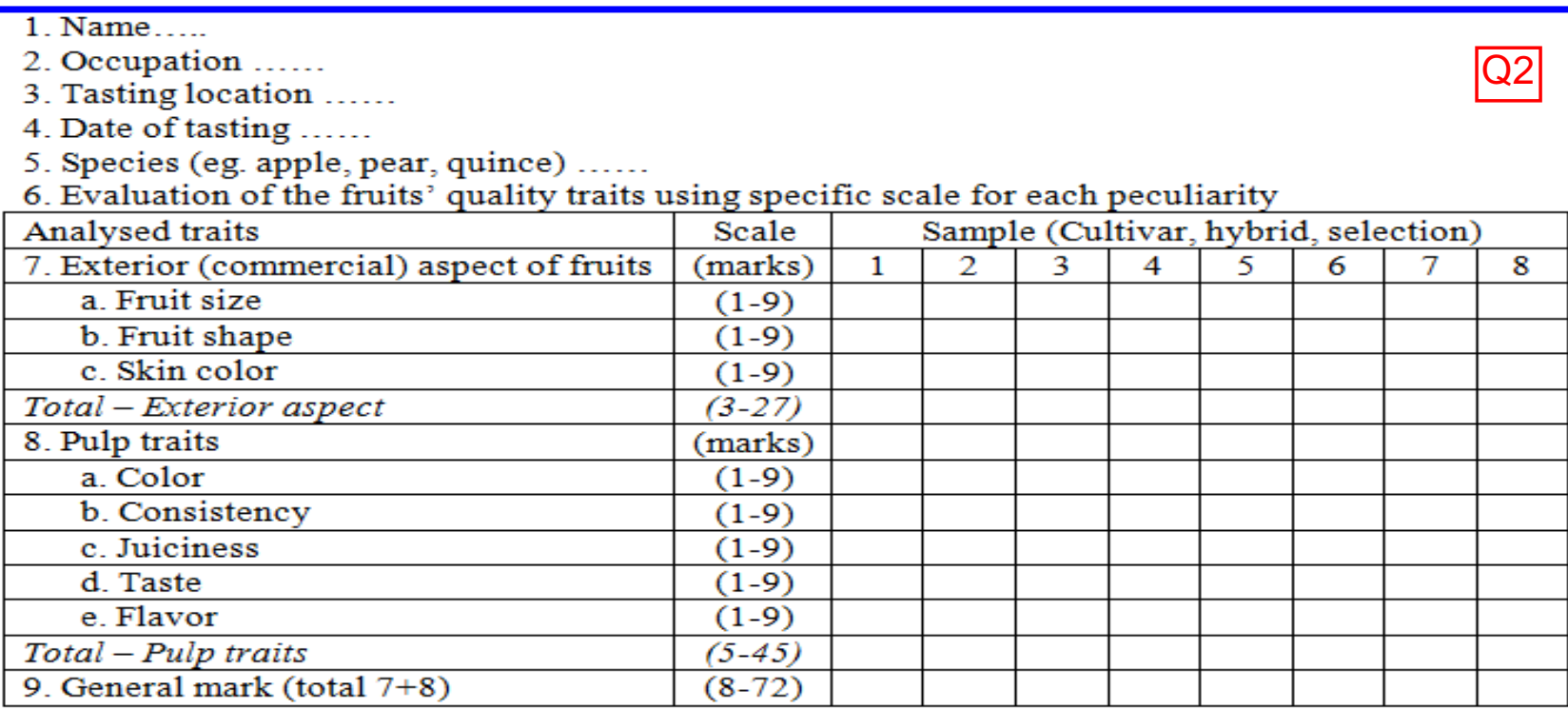

10. The quality of samples according to the marks scored

11. Overall comments regarding the samples ......

Fig. 2. Questionnaire for assessing fruit quality (cultivars, selections, hybrids) of apple, pear, quince (Q2) 


\section{Statistical analysis}

The marks were scored while keeping the samples neutral, as tasters did not know the evaluated cultivars, hybrids or selections, or any other details that might have influenced them. The marks were calculated as means per gender (as the rate was $50-50 \%$ among the tasters) so that the calculated data may emphasise if there are any differences within customer's gender and if this criteria influences the perception and preferences upon fruit quality.

The differences among the evaluated cultivars were analysed using analysis of variance, general linear model procedure (one way ANOVA and LSD test at $\mathrm{P} \leq 0.05 ; 0.01$; 0.001 level). The cultivars were compared with the mean of experience, used as control. Split-plot data were analyzed to check the differences of marks attributable to each trait and cultivar (sample), but also to consumers' gender category.

The variability within marks among tasters was analysed by calculating the Coefficient of Variation (CV\%), while the interactions between traits were identified using Pearson's correlation coefficient between variables and linear regression. All statistical data were analysed using Microsoft Excel spreadsheet software, based on consecrated formulas.

\section{Results}

It was ascertain that the local market is abundant in apples, but overall prevail fruits imported from different countries, than the fruits produced in Romania (Fig. 3). The local production is to be found more on the agro-markets (approx. 35\%), than retailed in specialised shops or fruit displays in hypermarkets. Inside the large hypermarket chains, over $90 \%$ of the apples come from European Union (EU), not from Romanian orchards.

Even though that Romania was a large producer of apples and numerous cultivars were created by Romanian pomologists (Coman et al., 2012; Militaru et al., 2013; Sestras, 2004), the assortment available now days for consumers is entirely covered by worldwide spread cultivars, and local or national production of apples is not significantly present on the market.

\section{Biometric traits, solid soluble content and fruit firmness}

Among the eight studied cultivars that fulfilled the existence criteria on the market mentioned in the methodology, the largest fruits (both in regard of height, diameter, volume and weight) were scored for 'Jonagold' (Table 1); this may be attributed to the triploidy of the cultivar, feature that is known to induce large fruits (Sestras, 2004). There were inferior differences within the mean of experiment and fruit size of several cultivars: 'Granny Smith', 'Golden Delicious' and 'Jonathan'.

With the exception of 'Red Delicious' which had tronconic/ flattened conical fruits, all the others had round forms, like oblate ('Jonathan', 'Golden Delicious', 'Granny Smith', 'Idared', illustrated by smaller values of the shape index) or round oblong ('Jonagold', 'Florina', 'Braeburn'). The soluble solids content ranged between 11.3-14.5 ${ }^{\circ}$ Brix, whereas a high content for sugars was obtained for 'Florina', 'Golden Delicious', 'Red Delicious' and smaller values were noted for 'Jonathan', 'Idared', 'Granny Smith' and 'Jonagold'.

It is worth mentioning that the larger fruit of 'Jonagold' had the smallest value for firmness $\left(64.2 \mathrm{~N} / \mathrm{cm}^{2}\right)$. Among the studied cultivars, small values (equivalent to a softer pulp) were scored also for 'Granny Smith' and 'Idared', although these are recon as having a firm pulp (Sestras et al., 2006).

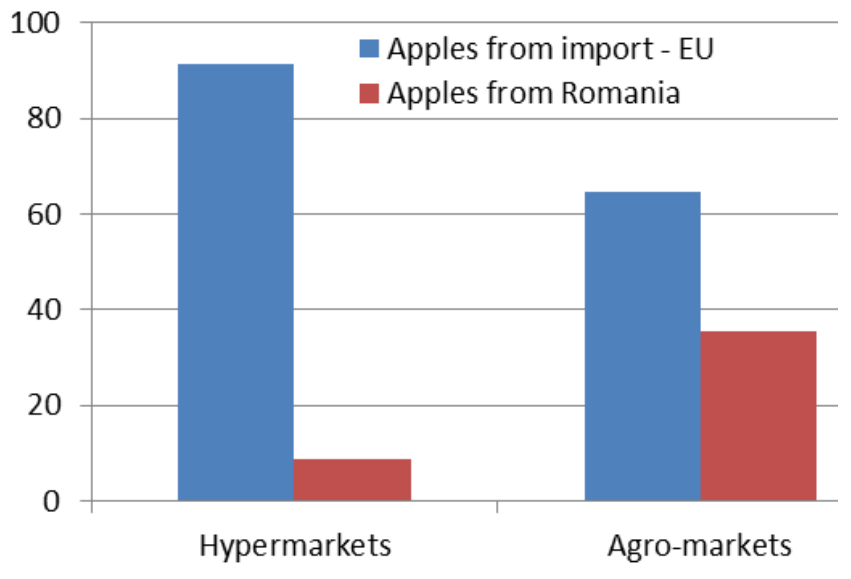

Fig. 3. The origin and distribution of apples in Cluj-Napoca (Romania vs. EU, markets vs. hypermarkets) (based on data registered during January-March for two consecutive years)

Table 1. Specific determinations data for apple fruit prior tasting evaluation

\begin{tabular}{|c|c|c|c|c|c|c|c|c|}
\hline \multirow[b]{2}{*}{ No. } & \multirow[b]{2}{*}{ Cultivar } & \multicolumn{7}{|c|}{ Main biometric traits, soluble sugar and firmness of fruits } \\
\hline & & $\begin{array}{l}\text { Height } \\
(\mathrm{mm})\end{array}$ & $\begin{array}{l}\text { Diameter } \\
(\mathrm{mm})\end{array}$ & $\begin{array}{c}\text { Shape index } \\
\text { (H/D) }\end{array}$ & $\begin{array}{c}\text { Volume } \\
(\mathrm{ml})\end{array}$ & $\begin{array}{c}\text { Weight } \\
\text { (g) }\end{array}$ & $\begin{array}{c}\text { Soluble solids } \\
\text { ( }{ }^{\circ} \text { Brix) }\end{array}$ & $\begin{array}{l}\text { Firmness } \\
\left(\mathrm{N} / \mathrm{cm}^{2}\right)\end{array}$ \\
\hline 1. & 'Golden Delicious' & $60.8^{\circ 0}$ & $71.4^{\circ}$ & 0.85 & $209.0^{\circ}$ & $146.5^{\circ}$ & $14.2^{x}$ & 67.8 \\
\hline 2. & ‘Granny Smith’ & $61.2^{\circ 0}$ & $71.0^{\circ}$ & 0.86 & $208.0^{\circ \circ}$ & $144.0^{\circ}$ & $12.3^{(0)}$ & $64.3^{\circ}$ \\
\hline 3. & 'Braeburn' & 70.0 & 77.2 & 0.91 & 281.9 & 216.2 & 13.7 & $84.8^{x x}$ \\
\hline 4. & 'Jonagold' & $85.8^{\mathrm{xxx}}$ & $90.9^{\mathrm{xx}}$ & $0.94^{\mathrm{xx}}$ & $479.1^{\mathrm{xx}}$ & $302.8^{\mathrm{xxx}}$ & $12.3^{(0)}$ & $64.2^{\circ}$ \\
\hline 5. & 'Jonathan' & $59.6^{\circ 0}$ & 72.0 & $0.83^{\circ}$ & $209.3^{\circ 0}$ & $145.3^{\circ}$ & $11.3^{\circ 0}$ & 69.2 \\
\hline 6. & 'Red Delicious' & 68.1 & 80.8 & 0.84 & 300.4 & 202.7 & $13.8^{x}$ & 68.1 \\
\hline 7. & 'Florina' & 70.6 & 77.1 & 0.92 & 284.8 & 196.0 & $14.5^{\mathrm{xx}}$ & 67.7 \\
\hline 8. & 'Idared' & 69.6 & 79.6 & 0.87 & 297.9 & 199.2 & $12.3^{(0)}$ & 69.5 \\
\hline Mean & of experience (Control) & 68.2 & 77.5 & 0.88 & 283.8 & 194.1 & 13.1 & 69.4 \\
\hline & LSD $0.05 \%=$ & 3.9 & 6.0 & 0.05 & 41.0 & 34.8 & 0.8 & 5.0 \\
\hline & LSD $0.01 \%=$ & 6.4 & 9.9 & 0.06 & 56.8 & 57.6 & 1.4 & 8.3 \\
\hline & LSD $0.001 \%=$ & 12.0 & 18.6 & 0.07 & 78.9 & 107.8 & 2.5 & 15.6 \\
\hline
\end{tabular}


144

\section{Tasting panel evaluation (Sensory evaluation)}

The data obtained by the tastel panel evaluation forms, regarding the commercial aspect of apples and pulp traits, are given in Table 2 (data corresponding to Questionnaire 1) and Table 3 (data corresponding to Questionnaire 2).

Based on the marks scored in Q1, the best color appearance was obtained for 'Braeburn' and 'Red Delicious' cultivars. Statistical assured differences for these two were scored also on the 1-9 scale questionnaires (Q2), but on hedonic scale also 'Granny Smith' had significant superior differences (for P 1\%). A less appreciated skin color was noted on both tasting panel forms for 'Golden Delicious' and 'Florina'. The most distinct inferior differences compared with the mean of experiment for skin color were scored for 'Florina' apples, but only on Q2. The highest values (general mark) scored in both questionnaires based on the tasters evaluation were noted for 'Braeburn' cultivar, which was well appreciated also for the commercial aspect as well as for intrinsic quality traits (juiciness, taste, flavor).

For some traits, the tasters marks on Q1 and Q2 confirm the biometric determinations presented in Table 1 (e.g. fruit size, consistency).

It is interesting though that based on the two different tasting panel evaluation forms, with different scales for traits or with hedonic scale of 1 to 9 , the general marks vary in some cases. In fact, the data from Q1 and Q2 were correlated only for juiciness and taste, and with some tolerance, for fruit size (Fig. 4).

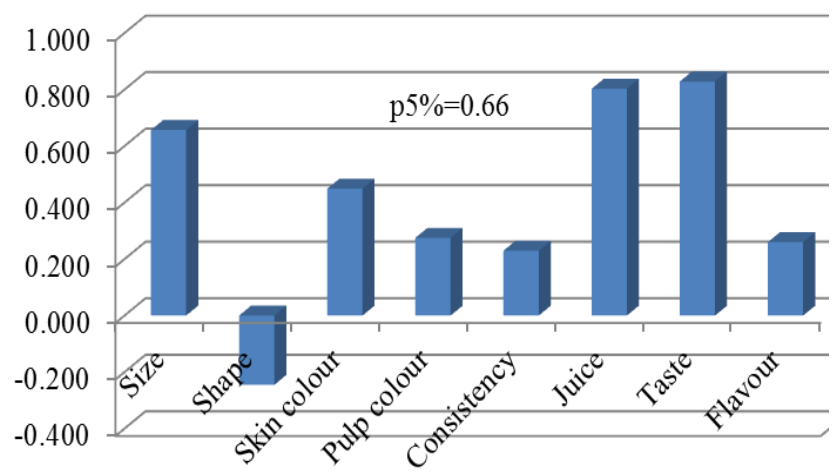

Fig. 4. Correlation among marks for fruit of different apple cultivars, after tasting evaluation using Questionnaires 1 and 2
Depending on the questionnaire, some contradictions were noted; this is the case for example of 'Golden Delicious' cultivar, which had smaller values compared with the control for fruit shape on Q1, but superior marks, therefore a well appreciated shape, based on Q2 scores. Also, the flavor of 'Golden Delicious' fruit was found to be good when Q1 data were analysed, but not that well acknowledged in Q2. The data illustrate the fact that sensory panel tasting has a high degree of subjectivity, not only due to different scales for evaluation and consumers preferences, but also due to assessment of sensory attributes or fruit characteristics, as well as consumers' disposal and sensitivity for panel rating. These aspects are not new (Seppä et al., 2013; Yahia, 1994) and hedonic bias and the influence of subjectivity are trying to be avoided by correlations among different tasting techniques and other measurements that might refer to fruit quality (Popper, 2015).

Regardless of the questionnaire used (Q1 or Q2) with the tasters, the higher score was noted for 'Braeburn' (Tables 2 and 3). 'Braeburn' distinguished mainly thorough Q1, having more significant superior differences; this is surely due to the more vast scale used for quality traits and the variability of marks, which was higher among the eight cultivars $(\mathrm{CV} \%=13.2)$ in Q1 than the one obtained in Q2 $(\mathrm{CV} \%=6.1)$. On the second panel evaluation form, 'Jonagold' followed closely the scores of 'Braeburn'. While Q1 assured a more wide dispersion of the marks, and therefore the cultivars were distinguished better as preferences among tasters, Q2 by the use of uniform scale determine an evident separation of the two cultivars, and practically homogenised (general marks between 54.2-55.4) the others, with smaller marks and less appreciated. In effect, all the cultivars may be scored as having 'Extra fruits' based on Q2 results. The equivalent of $\mathrm{Q} 2$ general marks are as follows: Extra (between 55-63); First Class ( $\left.\mathrm{I}^{\mathrm{t}}\right)$ (between 45-54); Second class $\left(\mathrm{II}^{\text {nd }}\right)$ (between 35-44); Inferior (less than 35). Surprisingly, the minim scores on Q2 were noted for the most spread and known cultivars in Romania, 'Golden Delicious' and 'Jonathan' respectively (Fig. 6). The subjectivity of the results is strongly sustained by the significant differences among general marks of 'Golden Delicious' and 'Jonathan' when Q1 and respectively Q2 were used as tasting panel forms (Figs. 5 and 6), considering that the samples came from the same batch, and the only aspects variable were the scales and the time of organoleptic evaluation (as mentioned in the methodology, Q2 was tasted after one week from Q1 evaluation).

Table 2. Organoleptic data for fruit quality evaluated with Questionnaire 1

\begin{tabular}{|c|c|c|c|c|c|c|c|c|c|}
\hline \multirow[b]{2}{*}{ Nr. } & \multirow[b]{2}{*}{ Cultivar } & \multicolumn{8}{|c|}{ Fruit traits evaluated by marks (different scales) } \\
\hline & & $\begin{array}{l}\text { Size } \\
(1-3)\end{array}$ & $\begin{array}{l}\text { Shape } \\
(1-3)\end{array}$ & $\begin{array}{c}\text { Skin color } \\
(1-5)\end{array}$ & $\begin{array}{c}\text { Pulp color } \\
(1-3)\end{array}$ & $\begin{array}{c}\text { Consistency } \\
(1-3)\end{array}$ & $\begin{array}{c}\text { Juiciness } \\
(1-5)\end{array}$ & $\begin{array}{l}\text { Taste } \\
(1-15)\end{array}$ & $\begin{array}{c}\text { Flavor } \\
(1-5)\end{array}$ \\
\hline 1. & 'Golden Delicious' & 2.5 & $2.1^{\circ 0}$ & $2.9^{000}$ & 2.5 & 2.5 & 3.6 & $11.7^{x}$ & $3.8^{x}$ \\
\hline 2. & 'Granny Smith’ & 2.7 & 2.7 & 4.2 & 2.4 & 2.3 & 3.3 & $6.2^{\circ 00}$ & $2.6^{\circ 0}$ \\
\hline 3. & 'Braeburn' & $2.9^{\mathrm{xx}}$ & $2.8^{\mathrm{x}}$ & 3.9 & 2.7 & $2.8^{\mathrm{xx}}$ & $4.3^{\mathrm{xxx}}$ & $13.9^{\mathrm{xxx}}$ & $4.8^{\mathrm{xxx}}$ \\
\hline 4. & 'Jonagold' & $3.0^{\mathrm{xxx}}$ & $2.7^{(\mathrm{x})}$ & $4.5^{x}$ & 2.4 & $3.0^{\mathrm{xxx}}$ & 3.5 & 8.6 & 2.9 \\
\hline 5. & 'Jonathan' & $2.0^{\circ 00}$ & $2.3^{(0)}$ & 3.7 & 2.4 & $2.0^{\circ \circ}$ & $2.7^{\circ 0}$ & $7.7^{\circ}$ & 2.8 \\
\hline 6. & 'Red Delicious' & $2.8^{x}$ & 2.4 & $4.3^{x}$ & 2.2 & 2.1 & 3.5 & 9.8 & 3.1 \\
\hline 7. & 'Florina' & $2.2^{\circ 000}$ & $2.3^{(\mathrm{o})}$ & $3.1^{\circ 0}$ & 2.4 & 2.2 & $2.8^{\circ}$ & 9.0 & 3.1 \\
\hline 8. & 'Idared' & 2.6 & $2.8^{\mathrm{x}}$ & 4.1 & 2.6 & 2.2 & 3.3 & 9.1 & 2.9 \\
\hline Meai & of experience (Control) & 2.6 & 2.5 & 3.8 & 2.4 & 2.4 & 3.4 & 9.5 & 3.3 \\
\hline & LSD $0.05 \%=$ & 0.2 & 0.3 & 0.5 & 0.8 & 0.3 & 0.5 & 1.5 & 0.5 \\
\hline & LSD $0.01 \%=$ & 0.3 & 0.4 & 0.6 & 1.0 & 0.4 & 0.7 & 2.0 & 0.7 \\
\hline & LSD $0.001 \%=$ & 0.4 & 0.5 & 0.8 & 1.3 & 0.5 & 0.8 & 2.5 & 0.9 \\
\hline
\end{tabular}


Table 3. Organoleptic data for fruit' quality evaluated with Questionnaire 2

\begin{tabular}{|c|c|c|c|c|c|c|c|c|c|}
\hline \multirow[b]{2}{*}{ No. } & \multirow[b]{2}{*}{ Cultivar } & \multicolumn{8}{|c|}{ Fruit traits evaluated by marks (hedonic scale, same for all traits } \\
\hline & & $\begin{array}{l}\text { Size } \\
(1-9) \\
\end{array}$ & $\begin{array}{l}\text { Shape } \\
(1-9)\end{array}$ & $\begin{array}{c}\text { Skin color } \\
(1-9)\end{array}$ & $\begin{array}{c}\text { Pulp color } \\
(1-9)\end{array}$ & $\begin{array}{c}\text { Consistency } \\
(1-9)\end{array}$ & $\begin{array}{c}\text { Juiciness } \\
(1-9)\end{array}$ & $\begin{array}{l}\text { Taste } \\
(1-9) \\
\end{array}$ & $\begin{array}{c}\text { Flavor } \\
(1-9)\end{array}$ \\
\hline 1. & 'Golden Delicious' & $4.5^{\circ 00}$ & $7.7^{(*)}$ & $6.3^{\circ}$ & 7.2 & 6.6 & 7.5 & $8.3^{*}$ & $6.1^{\circ}$ \\
\hline 2. & 'Granny Smith’ & $4.4^{\mathrm{ooo}}$ & $8.2^{\prime \prime}$ & $7.9 "$ & 7.0 & $8.1^{\prime \prime}$ & 7.1 & $4.2^{\circ 00}$ & 7.5 \\
\hline 3. & 'Braeburn' & $8.1^{\prime *}$ & 6.8 & $7.5^{(*)}$ & 7.1 & $7.8^{*}$ & $8.5^{*}$ & $8.7^{*}$ & $8.1^{*}$ \\
\hline 4. & 'Jonagold' & $8.8^{* * *}$ & 7.1 & 6.6 & 7.5 & 6.8 & 8.1 & 8.0 & $8.2^{* *}$ \\
\hline 5. & 'Jonathan' & $4.6^{\circ 00}$ & 7.6 & 7.1 & 8.0 & 6.7 & 7.0 & 6.8 & 6.4 \\
\hline 6. & 'Red Delicious' & $7.1^{(*)}$ & $6.0^{\circ \circ}$ & $7.6^{*}$ & $6.6^{\circ}$ & $5.8^{\circ 0}$ & 6.8 & 7.7 & 7.1 \\
\hline 7. & 'Florina' & 6.4 & 7.2 & $6.5^{(0)}$ & 7.8 & 7.2 & $6.3^{\circ}$ & 7.1 & 6.9 \\
\hline 8. & 'Idared' & 6.6 & $6.4^{\circ}$ & $6.2^{\circ o}$ & 7.8 & 7.4 & 7.4 & 6.9 & $5.7^{\circ 0}$ \\
\hline Mean & f experience (Control) & 6.3 & 7.1 & 7.0 & 7.4 & 7.1 & 7.3 & 7.2 & 7.0 \\
\hline & LSD $0.05 \%=$ & 0.9 & 0.7 & 0.6 & 0.8 & 0.7 & 1.0 & 1.1 & 0.8 \\
\hline & LSD $0.01 \%=$ & 1.2 & 1.0 & 0.8 & 1.1 & 1.0 & 1.4 & 1.5 & 1.1 \\
\hline & LSD $0.001 \%=$ & 1.7 & 1.4 & 1.1 & 1.5 & 1.4 & 1.9 & 2.1 & 1.5 \\
\hline 40 & & & & $=13.2$ & 64.0 & & & & $=6.1$ \\
\hline 36.0 & & & & & 62.0 & & & & \\
\hline $\begin{array}{l}34.0 \\
32.0\end{array}$ & & & 30.2 & & 60.0 & & & & \\
\hline $\begin{array}{l}30.0 \\
28.0\end{array}$ & & & & 27.1 & 56.0 & & & & $\begin{array}{ll}55.4 & 54.4\end{array}$ \\
\hline $\begin{array}{l}26.0 \\
24.0\end{array}$ & & & & & 54.0 & & & & \\
\hline $22.0-$ & & & & & $\begin{array}{l}52.0 \\
50.0\end{array}$ & & & & \\
\hline
\end{tabular}

Fig. 5. Overall score for each apple cultivar based on Questionnaire 1 general marks

The study did not aimed to differentiate the cultivars upon fruit quality, which is never the less influenced by several factors (genetically, ecological, agricultural, manipulation and storage, subjectivity of organoleptic evaluation, the optimum moment of evaluation etc.), but more to compare the two tasting panel forms and the opportunity to have a vaster interval for scales used for important quality traits. The objective was similar with the one of Gatti et al. (2011) study: the two questionnaires were used to appreciate consumer preferences and establish a practical hedonic-sensory evaluation pattern.

Even though among the two questionnaires some surprisingly differences resulted, the overall mean of marks obtained for the studied cultivars were strongly correlated $\left(\mathrm{r}+0.736^{*}\right.$, Fig. 7$)$.

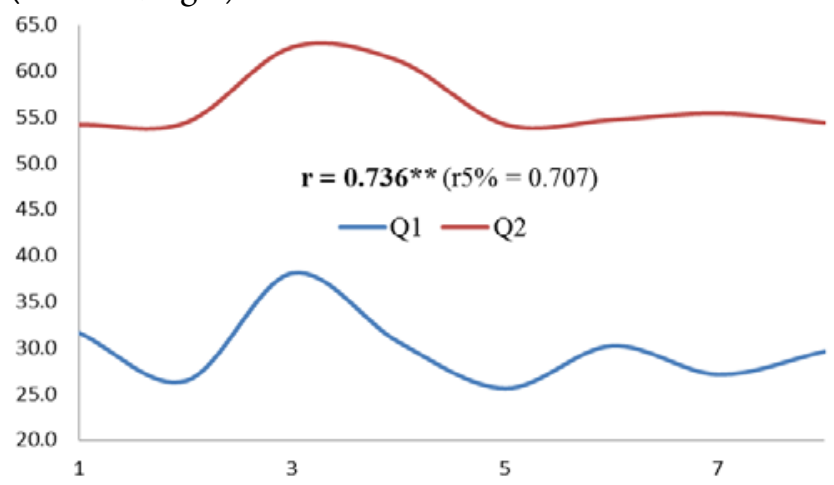

Fig. 7. Correlation among the general marks obtained for each apple cultivar on Questionnaires 1 and 2, with different scales of tasting evaluation
Fig. 6. Overall score for each apple cultivar based on Questionnaire 2 general marks

Positive correlation and the data registered indicate the close relationships among the quality traits' evaluation thorough Q1 and Q2. Therefore, regardless of the punctual discrepancies between the proposed panels (e.g. data for 'Golden Delicious'; Q2 higher marks for 'Jonagold', especially for fruit size, which were scored with the maximal mark), hedonic evaluations may be considered statistically relevant.

\section{Discussions}

Apple consumption in Romania oscillated during last years (e.g. $29.2 \mathrm{~kg} /$ capita in 1990; $45.4 \mathrm{~kg}$ in 2002; $22 \mathrm{~kg}$ in 2011), while the optimum consumption should be $90-100 \mathrm{~kg}$ (Popescu, 2012). Even though climate and soil conditions are favourable and apple tree growing is practiced on over $80 \%$ of the country's territory, Romania is a net importing country for apple (Pirvutoiu and Popescu, 2014). In a study based on a stratified questionnaire survey upon 100 individuals, all the interviewed people were accustomed to consume apples (Popescu, 2012). Among the evaluated cultivars, the preferred ones were 'Golden Delicious' (47\%), followed by 'Jonathan' (27\%), 'Florina' (21\%) and the most important apples attributes have been: freshness, taste, size, price, shape and color. Three cultivars are also among the ones studied hereby, based on their constant presence on the fruit market in Cluj-Napoca. The study illustrated the prevalence in Cluj-Napoca hypermarkets of well-known apple varieties spread worldwide, but also the absence or insignificant presence of Romanian apple varieties in some large retail groups in Romania. The value of the most spread cultivars in Cluj is confirmed also by 
146

the fact that three of them distinguish among the four different ideotypes included in the approximate consumer preference profiles by Sansavini et al. (2004): "American/European dessert apples are to be nice shaped, have a good appearance and color (mono-chrome preferred), large size, fine textured and juicy flesh, sweet and tart aromatic content, well balanced taste, good shelf life" (e.g. 'Golden Delicious', 'Red Delicious'); "European refreshing apples should be marked by juiciness, tartness, have good appearance, size and shape, mono-chrome or bi-colored, compact or soft flesh with good storability" (e.g. "Granny Smith'); "JFC, high quality apples, with good attractiveness as to shape and color (bi or tricolor) and excellent combination of juicy firm and crispy flesh (JFC), sweetness and high acid content" (e.g. the best known in this category, 'Braeburn').

It was unexpected though the classification on the last rank of the cultivar 'Jonathan'. In Romania, is still the most spread and well known, being for some years the standard, setting the regulations for fruit quality; it was also largely used in breeding programs as quality inducing genitor (Popescu, 2012). It is possible that the replacement of it from the European assortment is due to insufficient productivity in regard to the new demands, sensitivity to diseases and pests (it is intensely attacked by powdery mildew in the climacteric conditions from Transylvania (Sestras et al., 2003; Mitre et al., 2009), but also fruit quality may be inferior to newer cultivars, obtained through breeding programs (Sestras, 2004).

Significant differences among cultivars were registered both for morphological and organoleptic characteristics of fruits. Solid soluble content ranged from 11.3\% ('Jonathan') to $14.5 \%$ ('Florina'); data are similar with other reports for apple fruit (Cmelik et al., 2007; Hecke et al., 2006; Seppä, 2014). For commercial appearance of the fruits, in both questionnaires were highlighted 'Idared', 'Granny Smith', 'Braeburn' and especially 'Jonagold'.

The differences among tasters panel marks for commercial aspect were underscored by the amplitude of marks for intrinsic quality traits, especially in regard to taste and flavor. These differences were discussed after statistical analysis and were a big debate issue, trying to understand the reason of such diversity in evaluations. The tasters were asked to answer which of the two questionnaires was more objective in evaluating the fruit quality; 27 out of 40 (67.5\%) answer in favour of Q1, and the arguments are presented in Table 4.

Because for Q2 majority of respondents pointed that promotes traits of commercial reasons, respectively fruit appearance, than those regarding intrinsic sensorial quality, there were computed several indicators for analysing the possible associations between price (lei/Kg; 1 Romanian lei =
0.22 Euro) and all traits of fruit commercial appearance of apples (Fig. 8). The calculated parameters were the correlation coefficients $(r)$, the coefficients of determination $\left(\mathrm{R}^{2}\right)$ and regression equations; this data pointed out that there is no statistical assured correlation among the price and the commercial aspect of apples, given by size, shape and skin color, in both Q1 and Q2 respectively. Never the less, frequent consumers of domestic apples were more willing to pay a higher price than the less frequent eaters (Seppä, 2014).

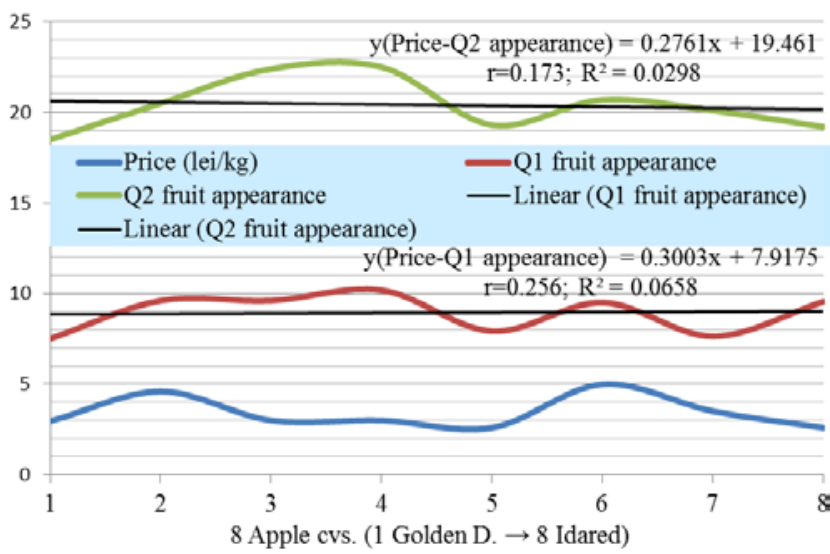

Fig. 8. The correlation coefficients ( $r$ ), the coefficients of determination $\left(\mathrm{R}^{2}\right)$ and regression equations $(\mathrm{y})$ within the price and general marks for commercial aspect in Q1 and Q2

The differences based on the marks given by male and female tasters are given in Fig. 9. For this, it was considered only Questionnaire 1, as it was more appreciated by the majority of students.

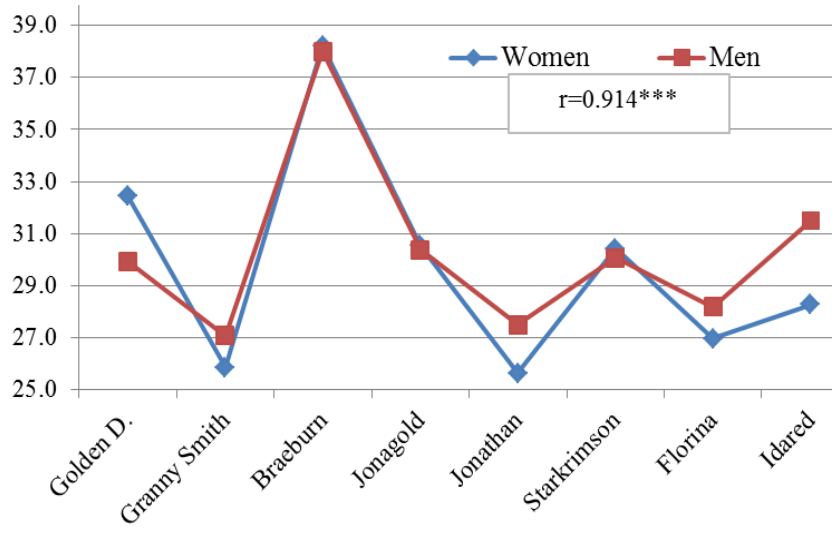

Fig. 9. Correlation based on tasters' gender among quality traits marks in Q1

Table 4. The opinions of tasters about the most relevant questionnaire

\begin{tabular}{|c|c|c|}
\hline Question & Questionnaire 1 & Questionnaire 2 \\
\hline The best questionnaire & 27 respondents from $40(67.5 \%)$ & 13 respondents from $40(32.5 \%)$ \\
\hline $\begin{array}{l}\text { Arguments; advantages; } \\
\text { disadvantages }\end{array}$ & $\begin{array}{l}\text { - Not all the traits have the same significance } \\
\text { when considering the quality of fruit, therefore, } \\
\text { different scales are desirable. } \\
\text { - A cultivar may have a very pleasant commercial } \\
\text { aspect, but the taste and flavour to be disliked; } \\
\text { - A larger scale gives the opportunity to be more } \\
\text { objective for marking the traits. }\end{array}$ & $\begin{array}{l}\text { - A wider and equal grading scale for all quality features offers } \\
\text { premises of a more suggestive overall score. } \\
\text { - The marks for the commercial aspect harmonized the } \\
\text { differences among the marks for intrinsic quality traits, } \\
\text { therefore, the ranks may be similar between the two } \\
\text { questionnaires when considering general marks. }\end{array}$ \\
\hline
\end{tabular}


The correlation coefficient shows a close connection, therefore a direct and positive relation $\left(\mathrm{r}=+0.914^{* * *}\right)$ among the marks evaluated in regard to the tasters' gender. The data points out that female respondents tend to be more severe in evaluation ('Idared', 'Jonathan', 'Florina', 'Granny Smith') and appreciate a sweet taste of fruit. Besides, females gave higher marks to 'Golden Delicious', which is less acidulate. The debate of the results confirms that girls dislike the sour-astringent fruit, while boys do like acidulated fruit. Even more, Racskó et al. (2009) stated that females gave higher importance ratings for most attributes than males.

'Braeburn' was confirmed as having a high quality fruit (Sansavini et al., 2004) being marked by the highest quality taste (average grade 13.9 on scoring scale 1-15) and also for fruit flavor. 'Granny Smith', a commercially attractive-looking fruit (Harker, 200), received only an average of 6.2 for fruit taste and 2.6 for flavor. 'Granny Smith' presented one of the largest value for the coefficient of variation for tasters' marks given for taste (Fig. 10), this variety being less appreciated by women than men.

Given by specific traits, any cultivar may be (extremely) liked and disliked by consumers, with vast differences depending on the region and its specific cuisine, consumers' age and gender, education, know-how (trained tasters) etc. (Abbott et al., 2004; Jemrić et al., 2012b; Jönsson and Nybom, 2008; Seppä et al., 2013).

Although 'Granny Smith' had a large variability for marks given for taste, among female and male tasters the marks were similar (Fig. 10); this pattern was seen also in the case of other cultivars: 'Golden Delicious', 'Braeburn', 'Red Delicious'. The high appreciation of the taste of 'Braeburn' fruit was completed by the homogeneity and uniformity of marks, $\mathrm{CV} \%$ having the smallest value, for both genders. A wider variability for taste marks was seen for 'Jonagold' and 'Idared' (Fig. 10), suggesting that the male tasters had similar evaluation opinions, while female tasters gave marks that vary strongly.

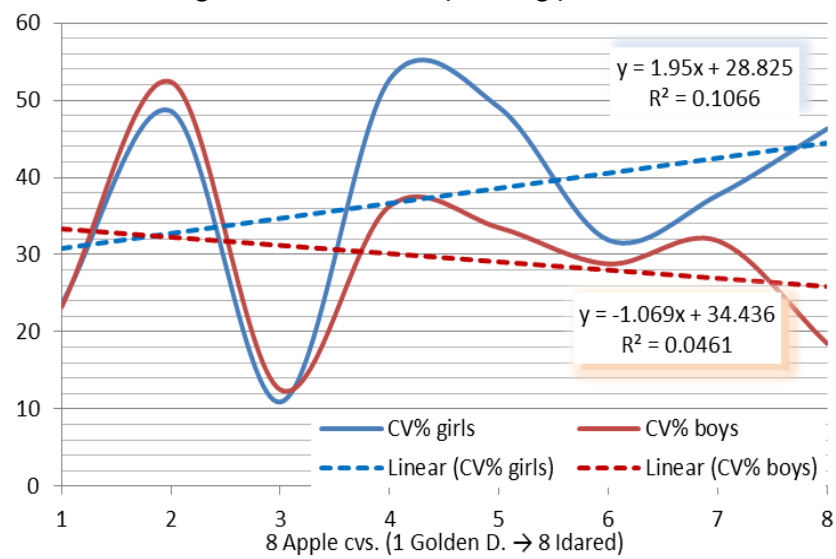

Fig. 10. Coefficient of variation (CV\%) for apple taste, evaluated using 1-15 scale (Q1), presented by gender $(50 \%$ male, $50 \%$ female)

The variability and bias for apples' flavor dependent on cultivar and tasters' gender have very different values (Fig. 11). The amplitude of marks and CV\% shows different appreciation between male and female tasters for flavor. There is an evident divergence for 'Braeburn' (3) and 'Jonagold' (4); in the same time female tasters gave totally homogenous marks for 'Golden Delicious' (1), while for 'Idared' (8) the flavor was distinct evaluated by them $(\mathrm{CV} \% \geq 40)$.

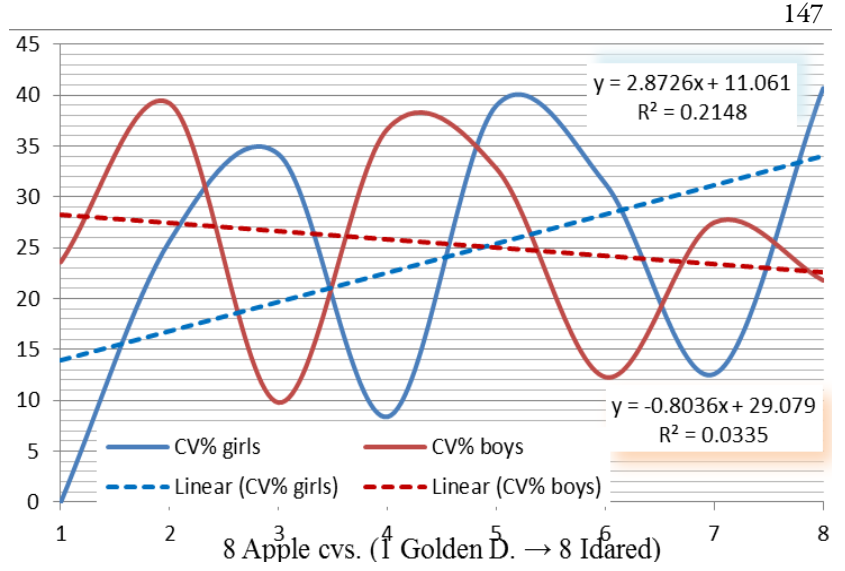

Fig. 11. Coefficient of variation (CV\%) for apple flavor, evaluated by $1-5$ scale (Q1), presented by gender ( $50 \%$ male, $50 \%$ female)

By analysing these results with the tasters, it was confirmed the taste axiom and that everyone has his/her own taste and taste cannot be wrong as it is ones' preference. Like in other studies (Jönsson and Nybom, 2008), taste and flavor, associated with optimum juiciness, were considered the most important quality traits, which can make the separation between cultivars and assure the appreciation on the market.

Considering the high relevance of the taste, as an essential quality trait, it was acknowledged that a hedonic scale (1-9) for all the evaluated characteristics is not assuring a complete and objective result. It is therefore recommended that the panel evaluation forms should be reassessed, and probably the use of different scales might be a proper solution for reducing the bias; in this case, the 1-15 scale for taste assured a more appropriate image of the tasters' preferences.

Apple breeders could efficiently use sensory evaluation for screening breeding selections (Endrizzi et al., 2015; Hanson et al., 2000). Even though sensory tests have become increasingly sophisticated as they are used in research to understand perception (Baldwin et al., 2007; Harker et al., 2008; Seppä, 2014), in apple breeding they could be more simple, but efficient in rapidly and accurate evaluation of large number of samples or for quality assurance of selected biological materials (Kappel, 1995). This is why a proper evaluation panel questionnaire is essential, established in order to assure an objective image and to illustrate as much differences as possible between cultivars and hybrids or selections, so that apple breeders may have a clear idea about the market demands and consumers' preferences.

\section{Conclusions}

The study indicates the absence, or insignificant presence, of Romanian apple varieties on the market. Cultivars like 'Braeburn', 'Golden Delicious', 'Jonagold' were highly appreciated, while some others, such as 'Granny Smith', well rated in Western Europe, were not preferred by tasters. Inconsistency of the market, prices and foreign assortment on Romanian market was illustrated by the lack of a statistical correlation between overall fruit quality and their cost price. Sensory panel evaluations remain the supreme test in characterization and assessment of apple cultivars' quality. Between the two questionnaires proposed to tasters, the more adequate one was the one using different scales, chosen in 
148

accordance with the importance of the quality trait evaluated (e.g. 1-15 for apple taste). The most appropriate pattern of fruit quality interpretation (type of questionnaire for panel evaluation) could offer useful information regarding the level of apples' acceptance, but also the perception capacity for distinctive fruit traits by consumers. Even more, a competent panel evaluation form might be the base needed by apple breeders for illustrating the market demands and give proper directions when considering new cultivars, on a legitimate tasters' evaluation.

\section{Acknowledgements}

This paper was published under the frame of European Social Fund, Human Resources Development Operational Programme 2007-2013, project no. POSDRU/159/1.5/S/132765.

\section{References}

Abbott JA (1999). Quality measurement of fruits and vegetables. Postharvest Biology and Technology 15(3):207-225.

Abbott JA, Saftner RA, Gross KC, Vinyard BT, Janick J (2004). Consumer evaluation and quality measurement of fresh-cut slices of 'Fuji', 'Golden Delicious', 'GoldRush' and 'Granny Smith' apples. Postharvest Biology and Technology 33(2):127-140.

Ardelean M (1994). Horticultural plant breeding - guidelines for practical lessons. Tipo Agronomia, Cluj-Napoca (in Romanian).

Baldwin EA, Plotto A, Goodner K (2007). Shelf-life versus flavorlife for fruits and vegetables: how to evaluate this complex trait. Stewart Postharvest Review 3(1):1-10.

Bignami C, Scossa A, Vagnoni G (2003). Evaluation of Old Italian apple cultivars by means of sensory analysis. Acta Hort 598:85-90.

Bonany J, Brugger C, Buehler A, Carbó J, Codarin S, Donati F, Schoorl F (2014). Preference mapping of apple varieties in Europe. Food Quality and Preference 32:317-329.

Byrne DH (2012). Trends in fruit breeding. p. 3-36. In: Fruit Breeding Springer US.

Cimpoieş G, Bucarciuc V, Caimacan I (2001). Apple cultivars., Ed. Ştiinta Chişinău (in Romanian).

Cmelik Z, Zadravec P, Tojnko S, Schlauer B, Vogrin A, Unuk T (2007). Sensory evaluation of fruit of some organically grown scab-resistant apple cultivars. Acta Hort 737:53-58.

Coman M, Militaru M, Butac M (2012). Fruit varieties breeding in Romania: from the beginning to present. Annals of the Academy of Romanian Scientists 1(1):43-52.

Denver S, Jensen JD (2014). Consumer preferences for organically and locally produced apples. Food Quality and Preference 31:129-134.

Endrizzi I, Torri L, Corollaro ML, Demattè ML, Aprea E, Charles M, Biasiolia F, Gasperi F (2015). A conjoint study on apple acceptability: Sensory characteristics and nutritional information. Food Quality and Preference 40:39-48.

Evans K, Brutcher L, Konishi B, Barritt B (2010). Correlation of sensory analysis with physical textural data from a computerized penetrometer in the Washington State University apple breeding program. HortTechnology 20(6):1026-1029.

Gatti E, Di Virgilio N, Magli M, Predieri S (2011). Integrating sensory analysis and hedonic evaluation for apple quality assessment. Journal of Food Quality 34(2):126-132.

Hampson CR, Quamme HA, Hall JW, MacDonald RA, King MC, Cliff MA (2000). Sensory evaluation as a selection tool in apple breeding. Euphytica 111(2):79-90.

Hampson CR, Quamme HA (2000). Use of preference testing to identify tolerance limits for fruit visual attributes in apple breeding. HortScience 35(5):921-924.

Harker FR, Kupferman EM, Marin AB, Gunson FA, Triggs CM (2008). Eating quality standards for apples based on consumer preferences. Postharvest Biology and Technology 50(1):70-78.

Harker FR, Maindonald J, Murray SH, Gunson FA, Hallett IC, Walker SB (2002). Sensory interpretation of instrumental measurements 1 : texture of apple fruit. Postharvest Biology and Technology 24(3):225-239.

Harker FR, Maindonald JH, Jackson PJ (1996). Penetrometer measurement of apple and kiwifruit firmness: operator and instrument differences. Journal of the American Society for Horticultural Science 121(5):927-936.

Harker R (2002). Improve fruit quality to increase demand. Good Fruit Grower 53(3):27.

Hecke K, Herbinger K, Veberič R, Trobec M, Toplak H, Štampar F, Keppel H, Grill D (2006). Sugar-, acid-and phenol contents in apple cultivars from organic and integrated fruit cultivation. European Journal of Clinical Nutrition 60(9):1136-1140.

Janick J, Moore JN (Eds.) (1996). Fruit breeding, tree and tropical fruits (Vol. 1). John Wiley \& Sons.

Jemrić T, Fruk G, Čiček D, Skendrović Babojelić M, Šindrak Z (2012a). Preliminary results of fruit quality of eight Croatian local apple cultivars. Agriculturae Conspectus Scientificus 77(4):223-226.

Jemrić T, Fruk G, Kortylewska D, Aljinović S (2012b). Postharvest quality and sensory characteristics of 'Granny Smith' apple treated with SmartFresh ${ }^{\text {tx }}$ (1-MCP). Agriculturae Conspectus Scientificus 77(4):211-215.

Jenks MA, Bebeli P (2011). Breeding for fruit quality. John Wiley and Sons Inc, Oxford.

Jönsson Å, Nybom H (2008). Consumer evaluation of scabresistant apple cultivars in Sweden. Agricultural and Food Science 15(4):388-401.

Kappel F, Fisher-Fleming R, Hogue EJ (1995). Ideal pear sensory attributes and fruit characteristics. HortScience 30(5):988-993.

Kroll BJ (1990). Evaluating rating scales for sensory testing with children. Food Technology 44(11):78-80, 82, 84, 86.

Langford G (2000). Evaluation - the key to success of new varieties. Compact Fruit Tree 33:9-11.

Militaru M, Braniste N, Butac M, Sestras A, Sotiropoulos T, Lukić M, Ambrozič Turk B, Dzhuvinov V (2013). Review 
of pome fruit breeding in Balkan. Acta Hort 981:177-184.

Miller S, Hampson C, McNew R, Berkett L, Brown S, Clements J, Crassweller R, Garcia E, Greene D, Greene G (2005). Performance of apple cultivars in the 1995 NE-183 regional project planting: III. Fruit sensory characteristics. Journal of the American Pomological Society 59(1):28-43.

Mitre I, Mitre V, Ardelean M, Sestras R, Sestras A (2009). Evaluation of old apple cultivars grown in central Transylvania, Romania. Notulae Botanicae Horti Agrobotanici Cluj-Napoca 37(1):235-237.

Pirvutoiu I, Popescu A (2014). Trends in Romania's fruit market. Annals of the University of Craiova-Agriculture, Montanology, Cadastre Series 43(2):164-169.

Popescu A (2012). Research regarding the trends in Romania's apple market. Analele Universitatii Craiova - seria Agricultura, Montanologie, Cadastru XLII(2):408-413.

Popper R, Kroll JJ (2005). Conducting sensory research with children. Journal of Sensory Studies 20:75-87.

Popper R, Kroll JJ (2015). Consumer testing of food products using children. Peryam \& Kroll Research Corporation, USA.

Racskó J, Miller DD, Duarte EE, Szabó Z, Soltész M, Nyéki J, Szukics J (2009). Is consumer preference for apple driven only by fruit quality? Acta Hort 831:331-338.

Sansavini S, Donati F, Costa F, Tartarini S (2004). Advances in apple breeding for enhanced fruit quality and resistance to biotic stresses: new varieties for the European market. Journal of Fruit and Ornamental Plant Research 12(Sp 2):13-52.
Seppä L (2014). Domestic apple cultivars: Sensory descriptions and consumer responses. University of Helsinki, Faculty of Agriculture and Forestry, Department of Food and Environmental Sciences. Doctoral dissertation.

Seppä L, Railio J, Vehkalahti K, Tahvonen R, Tuorila H (2013). Hedonic Responses and Individual Definitions of an Ideal Apple as Predictors of Choice. Journal of Sensory Studies 28:346-357.

Sestras R, Ardelean M, Jircan D (2003). Performances of several "classical" apple varieties in the environment of middle Transylvania. Bulletin of University of Agricultural Sciences and Veterinary Medicine Cluj-Napoca. Horticulture 60:163.

Sestras R, Tamas E, Sestras A (2006). Morphological and genetic peculiarities of fruits in several winter apple varieties which confer resistance to damage. Agronomy Research 4(1):55-62.

Sestras R (2004). Horticultural plant breeding (in Romanian). Ed. AcademicPres. Cluj-Napoca.

Yahia EM (1994). Apple Flavor. p. 197-234. In: Janick J (Ed.). Horticultural Reviews, Chapter 6, Volume 16. John Wiley $\&$ Sons, Inc. 